\title{
Article
}

\section{A meta-ethnographic study of health care staff perceptions of the WHO/UNICEF Baby Friendly Health Initiative}

Schmied, Virginia, Thomson, Gillian, Sheehan, A, Burns, E, Byrom, Anna and Dykes, Fiona Clare

Available at http://clok.uclan.ac.uk/10990/

Schmied, Virginia, Thomson, Gillian ORCID: 0000-0003-3392-8182, Sheehan, A, Burns, E, Byrom, Anna and Dykes, Fiona Clare ORCID: 0000-0002-27287967 (2014) A meta-ethnographic study of health care staff perceptions of the WHO/UNICEF Baby Friendly Health Initiative. Women and Birth, 27 (4). pp. 242-249. ISSN 1871-5192

It is advisable to refer to the publisher's version if you intend to cite from the work. http://dx.doi.org/10.1016/j.wombi.2014.05.005

For more information about UCLan's research in this area go to http://www.uclan.ac.uk/researchgroups/ and search for <name of research Group>.

For information about Research generally at UCLan please go to http://www.uclan.ac.uk/research/

All outputs in CLoK are protected by Intellectual Property Rights law, including Copyright law. Copyright, IPR and Moral Rights for the works on this site are retained by the individual authors and/or other copyright owners. Terms and conditions for use of this material are defined in the policies page. 


\title{
A meta-ethnographic study of health care staff perceptions of the WHO/UNICEF Baby Friendly Health Initiative
}

\begin{abstract}
Background: Implementation of the Baby Friendly Health Initiative (BFHI) is associated with increases in breastfeeding initiation and duration of exclusive breastfeeding and 'any' breastfeeding. However, implementation of the BFHI is challenging.
\end{abstract}

Aim: To identify and synthesise health care staff perceptions of the WHO/UNICEF BFHI and identify facilitators and barriers for implementation.

Method: Seven qualitative studies, published between 2003 and 2013 were analysed using meta-ethnographic synthesis.

Findings: Three overarching themes were identified. First the BFHI was viewed variously as a 'desirable innovation or an unfriendly imposition'. Participants were passionate about supporting breastfeeding and improving consistency in the information provided. This view was juxtaposed against the belief that BFHI represents an imposition on women's choices, and is a costly exercise for little gain in breastfeeding rates. The second theme highlighted cultural and organisational constraints and obstacles to BFHI implementation including resource issues, entrenched staff practices and staff rationalisation of non-compliance. Theme three captured a level of optimism and enthusiasm amongst participants who could identify a dedicated and credible leader to lead the BFHI change process. Collaborative engagement with all key stakeholders was crucial.

Conclusions: Health care staff hold variant beliefs and attitudes towards BFHI, which can help or hinder the implementation process. The introduction of the BFHI at a local level requires detailed planning, extensive collaboration, and an enthusiastic and committed leader to drive the change process. This synthesis has highlighted the importance of thinking more creatively about the translation of this global policy into effective change at the local level.

Key words: Breastfeeding, Baby Friendly, Attitudes, Implementation, Health Professionals 


\section{Introduction}

Protection, promotion and support of breastfeeding is a major public health issue. In recognition of this in 1991, WHO/UNICEF launched its global Baby Friendly Hospital Initiative ${ }^{1}$, now known in Australia as the Baby Friendly Health Initiative (BFHI). The purpose of the BFHI was to support the development of an infrastructure by maternity care facilities which enabled them to implement ten auditable standards, the 'Ten Steps' ${ }^{2}$.The BFHI was developed to reverse the medicalisation of infant feeding that occurred during the twentieth century, symbolised by rigid determination of the frequency and duration of feeds, separation of mothers and babies and unnecessary supplementation of breastfeeding with infant formula. WHO/UNICEF established national teams in participating countries to co-ordinate and monitor implementation in hospitals. BFHI accreditation is issued to those who reach a minimum externally auditable standard in relation to the 'Ten Steps'. Key aspects include health professional education, providing appropriate antenatal information, encouraging skinto-skin contact, lactation support to include those mothers separated from their babies, avoiding unnecessary breast milk substitutes, keeping mothers and babies together, encouraging flexible, baby-led breastfeeding and offering mothers continued support once discharged from hospital ${ }^{3}$.

Implementation of the BFHI is associated with significant increases in breastfeeding initiation and duration of exclusive breastfeeding and any breastfeeding ${ }^{4}$. However, the actual process of implementation of such a comprehensive set of changes presents challenges including the need for endorsement from policy makers and local administrators, effective intra and interorganisational leadership, staff training as well as the ongoing aggressive marketing of infant formula ${ }^{5}$. Semenic et $\mathrm{al}^{5}$ in an integrative review of $\mathrm{BFHI}$ implementation literature also noted that the individual characteristics of staff may impact on implementation. The lack of attention given to understanding how personal characteristics of staff may impact on the uptake of innovation by organisations has been criticised ${ }^{6,7}$. 
There is a growing body of qualitative research exploring health care staff perceptions related to BFHI implementation and its impact on staff, practices, parents and infants. Useful insights can be gained from rigorous qualitative or mixed methods studies that have investigated in-depth the macro and micro features of health care organisations and professional practice that enable and constrain innovation and translation of evidence-based practice $^{7-9}$. To develop an in-depth understanding of the factors influencing BFHI implementation, a meta-ethnographic study was conducted to identify health care staff perceptions of the BFHI and facilitators and barriers to implementation; this is reported on in this paper.

\section{Method}

Meta-ethnographic investigation involves synthesising multiple qualitative studies focussed on a particular area of inquiry. The findings from each individual study are compared and contrasted against each other to synthesise a more nuanced understanding of the phenomenon. Noblit and Hare ${ }^{10}$ developed an insightful approach to synthesising qualitative studies. This approach provides a framework for identifying 'reciprocal' and 'refutational' translations across findings in multiple studies. These techniques have been further developed by others ${ }^{11,12}$ and qualitative syntheses are increasingly advocated, alongside meta-analysis, to inform health service policy and delivery ${ }^{13}$.

\section{Search strategy}

This search was conducted in May-June 2013 using the following databases: CINAHL, MEDLINE, Psychlit, PubMed, SCOPUS and the Cochrane Library. Search terms included: $\mathrm{BFHI}, \mathrm{BFHI}$, baby-friendly, baby friendly, ten steps, health service, maternity service, maternal health service, implement*, perceptions, attitudes, beliefs, experiences, practices, views. Included papers were published in English between 1991 (year the BFHI was launched) to May 2013, and needed to report on all or some of the following; staff attitudes 
and perceptions of the BFHI, their experiences of implementation processes and perceptions of constraints and enabling factors.

Exclusion criteria: Papers that referred indirectly to the BFHI, focused only on one step, focused on reporting outcomes of BFHI, or papers that related to experiences of mothers or families. Papers that explored health professional practices in maternity units related to breastfeeding (e.g. Burns et $\mathrm{al}^{14}$ ) that did not specifically focus on BFHI implementation were also excluded.

\section{Search results}

The search resulted in 4577 papers (see Figure 1). Following removal of duplicates (1345 papers), the titles of 3232 papers were reviewed and 2891 were removed as they did not meet the inclusion criteria. Abstracts of the remaining 341 papers were read and a further 295 papers were excluded. Forty-six papers were read in full. Of these 46 papers, a further 39 papers were excluded because they were quantitative studies or mixed methods studies that did not include qualitative data or address health care staff perspectives. Seven papers were identified and underwent a quality review (see Figure 1).

Insert figure 1 about here

\section{Data quality}

Seven papers were reviewed using the quality appraisal framework developed by Walsh and Downe ${ }^{15}$. Six papers were graded as B as they did not have a clear theoretical or methodological framework or did not demonstrate congruence between the findings and data presented. One paper by Thomson, Bilson and Dykes ${ }^{16}$ was graded as A-. Of the seven papers, three ${ }^{16-18}$ used a theoretical or conceptual framework to present or interpret the findings (see Table1). However, we found in the process of analysis that many of the themes 
identified in the included papers were descriptive and were not adequately abstracted or conceptualised.

\section{Insert Table 1 about here}

\section{Data extraction and synthesis}

The framework developed by Noblit and Hare ${ }^{10}$ guided data extraction and synthesis. This involved a seven phase approach including: identifying the area of interest, deciding what was relevant, reading and re-reading the studies, deciding how the chosen studies were related, translating the studies in relation to each another, synthesising translations and presenting the synthesis. Translating key concepts or interpretive metaphors from one study to another involved an idiomatic rather than a word-for-word translation. Two authors were assigned to read each paper and in addition the first author also read all of the papers. The themes reported in four papers ${ }^{17,19-21}$ were primarily descriptive for example, one paper ${ }^{20}$ reported findings using each of the ten steps. Three papers ${ }^{16,18,22}$ presented abstracted themes, using 'in vivo' codes or in a few instances a metaphorical statement for example, 'the quick fix ${ }^{18}$.

We began by synthesising the original researcher's interpretations of raw data, presented as themes in qualitative research papers, to facilitate the translation of one study into the next. The nature of the reported themes in the seven studies examined however, made it difficult to conduct reciprocal translation. Other authors have similarly reported this and Atkins et al. ${ }^{23}$ and Dickson-Woods et al. ${ }^{24}$ suggest in this instance that meta-ethnographic studies apply Schutz's ${ }^{25}$ notion of first, second and third order constructs. First order constructs represent participants' perspectives of the phenomenon under investigation. Second order constructs are the thematic statements or abstractions reported as study findings by the original authors The first and second order constructs are then synthesised to produce third order constructs; hence the meta-synthesis findings. Applying this approach, the research team worked 
systematically through the papers, reading and re reading papers to create a list of themes and or metaphors; these were juxtaposed and examined to see how they related to each other ${ }^{10}$. We then identified new integrative themes from the synthesised first order and second order constructs in each of the seven papers (see Table 2). Interpretations by the authors of individual studies were also utilised to ensure the quotes were examined in context.

Insert Table 2 about here

\section{Results}

The papers that were reviewed and synthesised were published between 2003 and 2013 with a notable increase in researchers studying professionals' perceptions of the BFHI since 2010. Four studies were conducted in Australia, one each in the UK, NZ and the USA. All seven studies were interpretive or descriptive qualitative studies. Three overarching themes were identified.

\section{Theme 1: BFHI - Desirable innovation or an unfriendly imposition?}

The studies included in this synthesis reported positive and negative staff attitudes towards the BFHI. From a positive perspective it was viewed as an intervention that would impact on the local level in healthier communities and a reduction in health care costs both locally and at a global level. These perceptions contrasted with other participants who held less favourable views towards BFHI in terms of 'other' workload commitments and priorities and concerns BFHI was 'mother unfriendly'.

\section{Healthy lives, healthy communities}

In UK and Australian studies, participants generally expressed a belief, commitment and passion towards breastfeeding and consequently valued the $\mathrm{BFHI}{ }^{16,18}$. The introduction of this award, and associated training, was perceived as important to enable staff to recognise 
breastfeeding not just as a 'choice' but rather the 'natural' method of infant feeding ${ }^{18}$. In two Australian studies the BFHI was viewed as a key strategy to improve breastfeeding rates, change cultural perceptions and values and improve the health and well-being of families and communities ${ }^{18,21}$ :

If you breastfeed your baby, it doesn't just have benefits here and now, it has benefits for the whole community further along the track. Then that also impacts on how the country develops as a nation and then it snowballs into looking at how everything works in the world (FG 1) ${ }^{18}$.

\section{Empowering professionals and improving practice}

The BFHI was considered to provide a clear direction for staff ${ }^{21}$. The requirements for training and education enabled staff to resolve their own personal experiences and prejudices around infant feeding as well as encourage and facilitate consistency and efficiency in providing breastfeeding support ${ }^{16,18,21}$. Participants identified how the training had enabled them to become 'better at what we do' 22; enhancing staff confidence in providing breastfeeding support, and helping women to resolve any concerns or issues ${ }^{16,17 \text {, }}$ 22.

if somebody is perceived to have a breastfeeding problem they are passed to $X$ or $Y$ (different health professionals) so it's almost like the health visitors don't have, or don't feel they have, the skill to deal with it and I think going through the course, we let them see they do have the skill ${ }^{16, p .262}$.

\section{Mother 'unfriendly'}

Alternatively, in some studies negative views about the BFHI were expressed. In two studies undertaken in Australia and the USA, some viewed the ten steps as an 'imposition' on women's choice ${ }^{17,18,21}$. Nickel et $\mathrm{al}^{17}$ for example, described a 'lack of collective efficacy' amongst staff who perceived they had to 'force breastfeeding' against women's decisions 


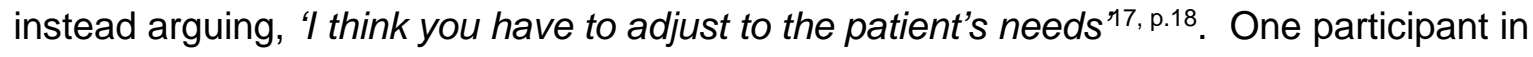
the study by Schmied et al stated:

I have actually come to the point that we are imposing something on them because some of them really don't want to.... Yes, because I have actually seen some staff trying hard and no matter what, that woman has to breastfeed ${ }^{18, ~}{ }^{\text {p.5 }}$.

Walsh, Pincombe and Henderson ${ }^{21}$ also reported negative views held by participants from non-BFHI hospitals about the ten steps and the impact on staff and their influences on women. Phrases used included 'mother unfriendly', 'breastfeeding Nazi's' or 'bullies'.

\section{Competing Priorities}

It was also evident that the BFHI, when weighed against other areas of clinical practice, was not always prioritised or considered necessary. For example, some stated that the cost of $\mathrm{BFHI}$ attainment was problematic in the context of budgetary constraints ${ }^{19,21}$. In the study by Walsh, Pincombe and Henderson ${ }^{21}$, participants from non-BFHI hospitals questioned the value of the award as they were 'performing just as well' (in relation to breastfeeding rates) as the hospitals that had BFHI status. The competing demands of clinical duties and prioritisation of administrative 'tasks ${ }^{\prime 18,19}$, meant that BFHI was considered to be idealistic rather than realistic within practice ${ }^{20}$ :

Because of time management... we are really having to get to grips with is [sic], once the baby is born, to get all the paperwork and computer work done, all the "important stuff"...I think that breastfeeding hasn't quite made it onto that more important than getting the paperwork done (sic) list just yet ${ }^{20, p .74}$.

\section{Overwhelmed by Requirements}

Within a number of the studies, the BFHI was considered to be an arduous process ${ }^{16,19,21 ; \text {; } a}$ mountain to climb' ${ }^{18}$ due to the constant need to train new staff members and the lack of skills and abilities in undertaking task requirements: 
Producing a written breastfeeding and infant feeding policy (Step 1) was seen as a daunting task (many participants had no prior experience in this area) ${ }^{21,0.601}$.

\section{Theme 2: Cultural and Organisational Constraints and Obstacles}

In all studies, no matter whether staff were generally positive towards the BFHI or not, many cultural and organisational issues or challenges to implementation were described.

\section{Spatial and Resource Constraints}

Staff described difficulties in BFHI implementation due to the geographical separation of mothers and infants (e.g. admission onto the neonatal unit); early discharge policies, inadequate staffing and busy units ${ }^{16,18,20-22}$. Others reported women's discomfort in establishing breastfeeding in the 'public' context of open bay postnatal wards ${ }^{20}$. Whilst practical problems emerged in terms of staff attending training events ${ }^{21}$; temporal and spatial constraints were considered to create 'quick fix' solutions through health professionals providing and/or encouraging formula milk:

You can give them the information to bottle feed really quick and then with breastfeeding they have to spend the time with them 22, p.29.

\section{Resistance and Non-Compliance}

Entrenched attitudes and practices towards care delivery led to 'resistance' and lack of confidence amongst staff members to implement the $\mathrm{BFHI}{ }^{19}$. A finding identified particularly amongst those who had more rather than less clinical experience in the study by Nickel et al. ${ }^{17}$; with some health professionals reliant on medical decisions for feeding practices. On occasion this led to staff giving babies bottles for example, babies with low blood sugars, as they were not confident in trying breastfeeding as a first option ${ }^{19}$ :

Resistance...People are set in their ways

'I said we'll start breastfeeding, and it sucked beautifully, but the nurse by the bedside was so afraid. She insisted on giving [the hypoglycaemic baby] a bottle 22, p.29. 
Staff members identified how they would not comply with some of the BFHI steps due to what they considered to be a weak evidence base for example, dummy use ${ }^{21}$. Others argued how compliance was not always possible due to the health status of the infant and/or mother, or the fact that neonatal infants had 'different' needs ${ }^{19,22}$ which could result in health professionals providing formula milk against a mother's wishes. Whilst this practice is contrary to BFHI guidance, it also raises legal and moral issues. Reddin, Pincombe and Darbyshire ${ }^{20}$ report how the loophole of medically indicated use in special care nurseries appears to be used to justify the use of formula for the convenience of staff as much as for the benefit of the baby.

\section{Rationalising, excusing and blaming}

In a number of the papers there was evidence of health professionals rationalising, excusing and blaming 'others' in relation to not adhering to BFHI implementation. It appeared that at times staff shifted responsibility for inaction on breastfeeding to the mother and to other staff or parts of the organisation ${ }^{20}$. For example, reasons cited for rooming-out included giving an 'exhausted mum a break' and settling a fractious baby ${ }^{18,19}$. Frustration was also expressed towards professionals not providing a consistent approach, and/or undermining the work undertaken to support a woman to breastfeed. Nickel et $\mathrm{al}^{17}$, found that differences in attitudes, beliefs, and practices were considered to vary across day and night shifts: On day shift, you can work and work and work with the mamma and not give it any formula and really work and she's breastfed all day. You give a report and you come in the next morning and they've had a bottle or formula during the night ${ }^{17, p .6}$.

Within other studies, staff members appeared to blame wider community and socio-cultural values $^{16,17,21,22}$. An entrenched bottle feeding culture and the fact that in western society babies are expected to follow routines according to what society thinks is 'correct' were used to rationalise non-compliance with the BFHI policies and procedures. Comments such as "not enough milk", "your milk is not strong enough", "bottle feeding is easier", "bottle fed 
babies sleep longer", "we can bottle feed while you have a sleep" were reported to deflate a woman's confidence at a time when she is vulnerable.

\section{Theme 3: Seizing the positive and being collaborative:}

Despite the complexity of implementing BFHI and staff resistance, some studies reported more enthusiasm and optimism for BFHI implementation, as stated by participants in Schmied et al's study, 'staff are 100 percent behind it'. The study by Thomson, Bilson and Dykes $^{16}$ in particular offers a fresh approach to BFHI implementation and emphasised the role of transformational leadership.

\section{Building on the positive, one step at a time}

Positive aspects of organisational culture in individual units were reported, for example: one thing this unit's always had is its positiveness ... and we are very good communicators with the mothers. And that's evident with the information that's passed onto them, and the sharing ${ }^{22, ~ p .30}$.

Another participant in Moore et al's study stated, "because of the camaraderie of the place... because of that I suppose we seem to have a good strategy (for BFHI) going." (Large hospital $B)^{19}$. Successes were also highlighted, 'I think now we do skin-to-skin better with our early, preterm babies'22, p.30. Encouragement came from noting that some steps were easier to implement or were already in-situ. For example, demand feeding (step 8) ${ }^{20}$ and 24 hour rooming-in (step 7) ${ }^{20}$ were well established and almost taken for granted practices. Skin to skin at birth (step 4) was also perceived to be a popular and desirable practice by most mothers, and considered a 'time saver' amongst staff:

It's [skin to skin] a time saver in the delivery suite as well because if you have your mother and baby skin to skin, that baby is safe with the mother,..., and more likely to latch on itself ${ }^{18, p .6}$.

\section{A dedicated and credible leader}


Leadership was seen as crucial. Most studies noted that having a dedicated and credible person to lead the change was essential, but many did not have this in place. At times leaders emerged 'ad hoc' simply because of their 'interest' or position in the organisation. In NZ, Moore et al reported:

It was just the fact that there was a lactation consultant position here so therefore that was the function of the $L C$ is to educate which is one of the biggest things ${ }^{19, p .5}$. The transformational approach reported by Thomson, Bilson and Dykes ${ }^{16}$, stands out as unique. Here the infant feeding coordinators were community-based peer supporters. These two leaders had attained high regard from hospital and community health professionals and were valued due to their 'flexible', 'realistic' approach and the fact that they were an ‘invaluable resource' for professionals:

Obviously they know about the issues regarding breastfeeding and getting mums going and supporting mothers and they have been doing that for years and years and plus they have got the commitment and the passion towards breastfeeding and really want this project to succeed ${ }^{16, p .260}$.

\section{Top-down approach: 'A directive is needed'}

High level management support was considered essential by some to implement BFHI, 'to be able to say we have been told we have to do this, so you (hospital management) need to support us' 18, p.5. In contrast Moore et $\mathrm{al}^{19}$ and Nickel et $\mathrm{al}^{17}$ report how the 'top down' directive from management prompted staff to act:

my medical director communicated that this was what we want to do ... as a result, people are committed because they 'have to be committed'17, p.6.

Caution was emphasised however, as taking a top down approach alone may increase the focus on measurement:

Well, things like audits, audits on breastfeeding stats, audits on skin-to-skin contact. Its measurements really we have them ongoingly ${ }^{19, p .6}$. 


\section{A 'softly-softly' collaborative approach}

Although top down support to implement change was highlighted by some, the change process also needed to engage all stakeholders in a collaborative and respectful way: (Infant Feeding Coordinators) are running this is a softly, softly approach and I like that: I don't like people telling me what to do, and I think that actually does engage because it makes us sit down and talk to them, they are approachable and available 16, p. 260

Thomson, Bilson and Dykes ${ }^{16}$ also report how it was essential to engage all the key players in the implementation process, which included women and peer supporters. In Walsh, Pincombe and Henderson ${ }^{21}$ one of the BFHI accredited hospitals had engaged the whole community with the support of the local peer support group from the Australian Breastfeeding Association ${ }^{21}$.

\section{Discussion}

The BFHI is a complex, multi-faceted strategy now in place in over 152 countries $^{26,28}$, however it remains challenging to implement and sustain in practice. The purpose of this meta-ethnographic study was to identify and synthesise health care staff perceptions of the $\mathrm{BFHI}$ and their views on the facilitators and barriers to implementation. The included studies were conducted in resource rich countries in over 30 facilities/sites and reported on various stages of BFHI implementation, including pre-implementation ${ }^{17}$. Sites where significant progress had been made in preparing for accreditation ${ }^{18,19,21,22}$ and sites that had achieved full BFHI accreditation ${ }^{21}$ or part thereof ${ }^{16}$ were also included. Some facilities included in the studies, while not accredited as BFHI, indicated they had already implemented a number or most of the steps; some non-BFHI facilities questioned the value of the award as they were 'doing it anyway'18, 21. The findings highlight that BFHI was valued by many participating staff for its capacity to change perceptions and prejudices and improve health and wellbeing of families through its ability to promote consistency in care delivery as well as empowering 
clinicians. However, others held more negative and sceptical views; a number of social, cultural and contextual barriers influencing BFHI implementation were identified.

Authors in the field of implementation science ${ }^{6-8,27,28}$ have conceptualised the multi-faceted and complex nature of translating evidence into policy and practice. In this metaethnographic study, resistance and non-compliance with the BFHI was related to length of service, with younger and/or less experienced staff considered more ready to learn and amenable to change ${ }^{17,20,21}$ and those who worked day shift perceived to be more committed than night staff ${ }^{17,18}$. Words and phrases used by participants also demonstrated the passion or emotional connection some held to breastfeeding and the BFHI. Greenhalgh et $\mathrm{al}^{7}$ and Cane et $\mathrm{al}^{6}$ emphasised the importance of individual characteristics of staff as crucial to achieving attitudinal and behavioural change. Understanding the impact of individual skill and experience is important because the meaning attached to an innovation can be either positively or negatively reframed and negotiated through discourses within and between organisations ${ }^{29}$. Increasingly social media and incentives are being used to reframe health innovations such as the BFHI making them more attractive to consumers and professionals ${ }^{30}$

The context within which an innovation is implemented also impacts on practice. RycroftMalone et $\mathrm{al}^{8,9}$ identified culture, leadership and evaluation as core contextual elements that both influence and reflect the capacity of an organisation for change. Organisations characterised by a learning culture value individuals, attend to group processes and systems, and demonstrate decentralised decision-making that is facilitative rather than directive with an emphasis on the relationship between the manager and the worker ${ }^{8}$. In this context senior administrators and managers are responsible to facilitate access to the resources necessary for implementation. Such facilitative management was rarely reported in these studies with most staff describing that they did not have the time to develop and implement relevant policies or to access training and education. 
Furthermore, some of the included studies reported an 'us and them' situation where other parts of the organisation such as theatre and recovery and NICU ${ }^{18,21,22}$, and other professionals ${ }^{18}$ were considered to be major obstacles to implementing BFHI. More concerning, in some studies, women themselves were blamed for the challenges to BFHI implementation $^{18}$. It is evident from the work of Thomson, Bilson and Dykes ${ }^{16}$ that an 'appreciative' or positive approach can be effective in achieving change. Change agents in this study successfully shaped the change process by framing and interpreting ${ }^{29}$ aspects of BFHI implementation in ways that engaged health professionals in all parts of the organisation. BFHI implementation is a complex innovation and for some overwhelming. Participants therefore favoured an incremental 'one step at a time' approach to implementation.

\section{Conclusion}

This meta-ethnographic study has examined the perceptions of health staff towards the BFHI. Health care staff hold variant beliefs and attitudes towards the BFHI, which can help or hinder the implementation process. The introduction of the BFHI at a local level requires detailed planning, extensive collaboration, and enthusiastic and committed leader/s to drive the change process. This synthesis has highlighted the importance of thinking more creatively about the translation of this global policy for example, by starting from the community and using experienced peer supporters in collaboration with health professionals, to effect change at the local level. 


\section{References}

1. WHO, UNICEF. Innocenti Declaration. On the protection, promotion and support of breastfeeding. Florence: UNICEF; 1991.

2. WHO. Protecting, promoting and supporting breast-feeding: the special role of maternity services. Geneva; 1989.

3. WHO., UNICEF. Global Strategy for Infant Feeding \& Young Child Feeding. Geneva: World Health Organization; 2003.

4. Beake S, Pellowe C, Dykes F, Schmied V, Bick D. A systematic review of structured compared with non-structured breastfeeding programmes to support the initiation and duration of exclusive and any breastfeeding in acute and primary health care settings. Maternal and Child Nutrition 2012; 8(2): 141-61.

5. Semenic S, Childerhose JE, Lauzière J, Groleau D. Barriers, facilitators, and recommendations related to implementing the Baby-Friendly initiative (BFI): An integrative review. Journal of Human Lactation 2012; 28(3): 317-34.

6. Cane J, O'Connor D, Michie S. Validation of the theoretical domains framework for use in behaviour change and implementation research. Implementation Science 2012; 7(1). 7. Greenhalgh T, Robert G, Macfarlane F, Bate P, Kyriakidou O. Diffusion of Innovations in Service Organizations: Systematic Review and Recommendations. The Milbank Quarterly 2004; 82(4): 581-629.

8. Rycroft-Malone J. The PARIHS framework - A framework for guiding the implementation of evidence-based practice. Journal of Nursing Care Quality 2004; 19(4): 297-304

9. Rycroft-Malone J, Seers K, Chandler J, et al. The role of evidence, context, and facilitation in an implementation trial: Implications for the development of the PARIHS framework. Implementation Science 2013; 8(1).

10. Noblit G, Hare R. Meta-ethnography: Synthesising qualitative studies. Newbury Park, CA: Sage; 1988. 
11. Downe S. Metasynthesis: A guide to knitting smoke. Evidence Based Midwifery 2008; 6(1): 4-8.

12. Finfgeld-Connett D, Johnson ED. Literature search strategies for conducting knowledge-building and theory-generating qualitative systematic reviews. Journal of Advanced Nursing 2013; 69(1): 194-204.

13. Campbell R, Pound P, Morgan M, et al. Evaluating meta-ethnography: systematic analysis and synthesis of qualitative research. Health Technology Assessment 2011; 15(43).

14. Burns E, Fenwick J, Sheehan A, Schmied V. Mining for liquid gold: Midwifery language and practices associated with early breastfeeding support. Maternal and Child Nutrition 2013; 9(1): 57-73.

15. Walsh D, Downe S. Appraising the quality of qualitative research. Midwifery 2006; 22(2): 108-19.

16. Thomson G, Bilson A, Dykes F. Implementing the WHO/UNICEF Baby Friendly Initiative in the community: A 'hearts and minds' approach. Midwifery 2012; 28(2): 258-64.

17. Nickel NC, Taylor EC, Labbok MH, Weiner BJ, Williamson NE. Applying organisation theory to understand barriers and facilitators to the implementation of baby-friendly: $A$ multisite qualitative study. Midwifery 2013.

18. Schmied V, Gribble K, Sheehan A, Taylor C, Dykes FC. Ten steps or climbing a mountain: A study of Australian health professionals' perceptions of implementing the baby friendly health initiative to protect, promote and support breastfeeding. BMC Health Services Research 2011; 11.

19. Moore T, Gauld R, Williams S. Implementing Baby Friendly Hospital Initiative policy: The case of New Zealand public hospitals. International Breastfeeding Journal 2007; 2.

20. Reddin E, Pincombe J, Darbyshire P. Passive resistance: Early experiences of midwifery students/graduates and the Baby Friendly Health Initiative 10 steps to successful breastfeeding. Women and Birth 2007; 20(2): 71-6. 
21. Walsh A, Pincombe J, Henderson A. An Examination of Maternity Staff Attitudes Towards Implementing Baby Friendly Health Initiative (BFHI) Accreditation in Australia. Maternal \& Child Health Journal 2011; 15(5): 597-609.

22. Taylor C, Gribble K, Sheehan A, Schmied V, Dykes F. Staff Perceptions and Experiences of Implementing the Baby Friendly Initiative in Neonatal Intensive Care Units in Australia. JOGNN - Journal of Obstetric, Gynecologic, and Neonatal Nursing 2011; 40(1): 2534.

23. Atkins $\mathrm{S}$, Lewin $\mathrm{S}$, Smith $\mathrm{H}$, Engel $\mathrm{M}$, Fretheim $\mathrm{A}$, Volmink J. Conducting a metaethnography of qualitative literature: Lessons learnt. BMC Medical Research Methodology 2008; 8: 21: 1-10.

24. Dixon-Woods M, Agarwal S, Jones D, Young B, Sutton A. Synthesising qualitative and quantitative evidence: A review of possible methods. Journal of Health Services Research and Policy 2005; 10(1): 45-53.

25. Schutz A. Collected papers, vol 1. The Hague: : Martinus Nijhoff, ; 1962.

26. UNICEF. The Baby-Friendly Hospital Initiative. 2012.

http://www.unicef.org/nutrition/index_24806.html (accessed July 30 2013).

27. Fixsen DL, Blase KA, Naoom SF, Wallace F. Core implementation components. Research on Social Work Practice 2009; 19(5): 531-40.

28. Rycroft-Malone J, McCormack B, Hutchinson AM, et al. Realist synthesis: illustrating the method for implementation research. Implementation Science 2012; 7(1).

29. Kezar A. Understanding and Facilitating Organizational Change in the 21st Century: Recent Research and Conceptualizations: ASHE-ERIC Higher Education Report; 2001.

30. Thomson G, Dykes F, Hurley MA, Hoddinott P. Incentives as connectors: Insights into a breastfeeding incentive intervention in a disadvantaged area of North-West England. BMC Pregnancy and Childbirth 2012; 12. 
Figure 1 Search Results

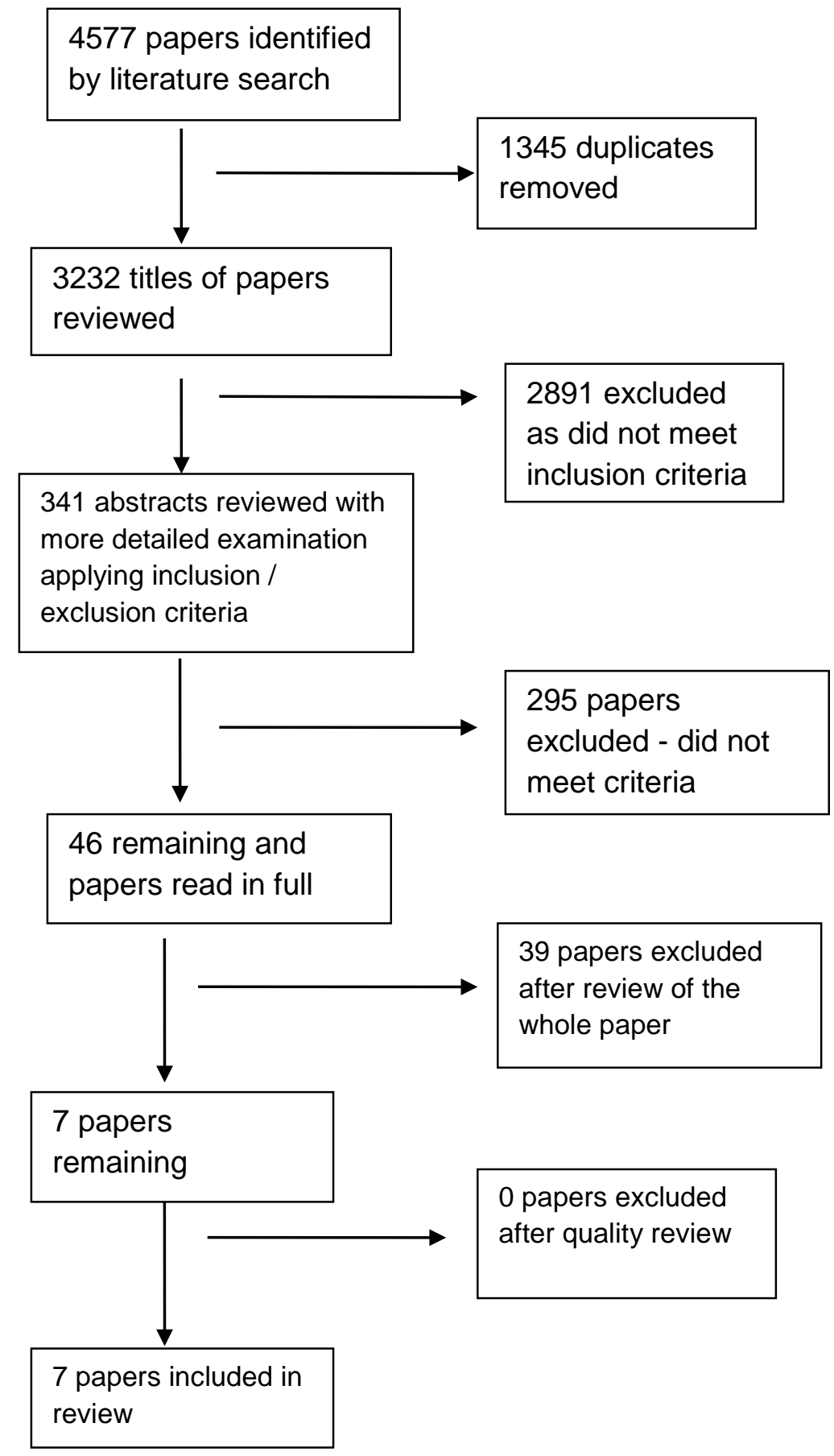


Table 1 - Included Studies

\begin{tabular}{|c|c|c|c|c|c|}
\hline $\begin{array}{l}\text { Author/ } \\
\text { location }\end{array}$ & Aim & Participants & Methodology & Methods & Results \\
\hline Moore, Gauld & To explore the & Purposive sample of 6 & Qualitative & Face to face Interviews & 8 descriptive themes presented: \\
\hline \& Williams, & processes and & lactation consultants & descriptive & Content analysis & - Policy development \\
\hline 2007 & challenges of & from 6 public hospitals & study & & - Relationship between hospital and \\
\hline (New & implementing & that represent the full & & & government policy \\
\hline \multirow[t]{11}{*}{ Zealand) } & National BFHI policy & range of public hospitals & & & - Communicating policy \\
\hline & at the hospital level. & in New Zealand. & & & - Overcoming barriers to \\
\hline & The key focus being & & & & communicating policy \\
\hline & an examination of & & & & - Difficulty achieving exclusive \\
\hline & Steps 1 and 2 of the & & & & breastfeeding targets \\
\hline & BFHI which involve & & & & - Policy evaluation \\
\hline & developing a & & & & - Discussing policy with other providers \\
\hline & breastfeeding policy & & & & - $\quad$ Size matters \\
\hline & and & & & & \\
\hline & training staff in order & & & & \\
\hline & to be able to & & & & \\
\hline
\end{tabular}


implement the

BFHI.

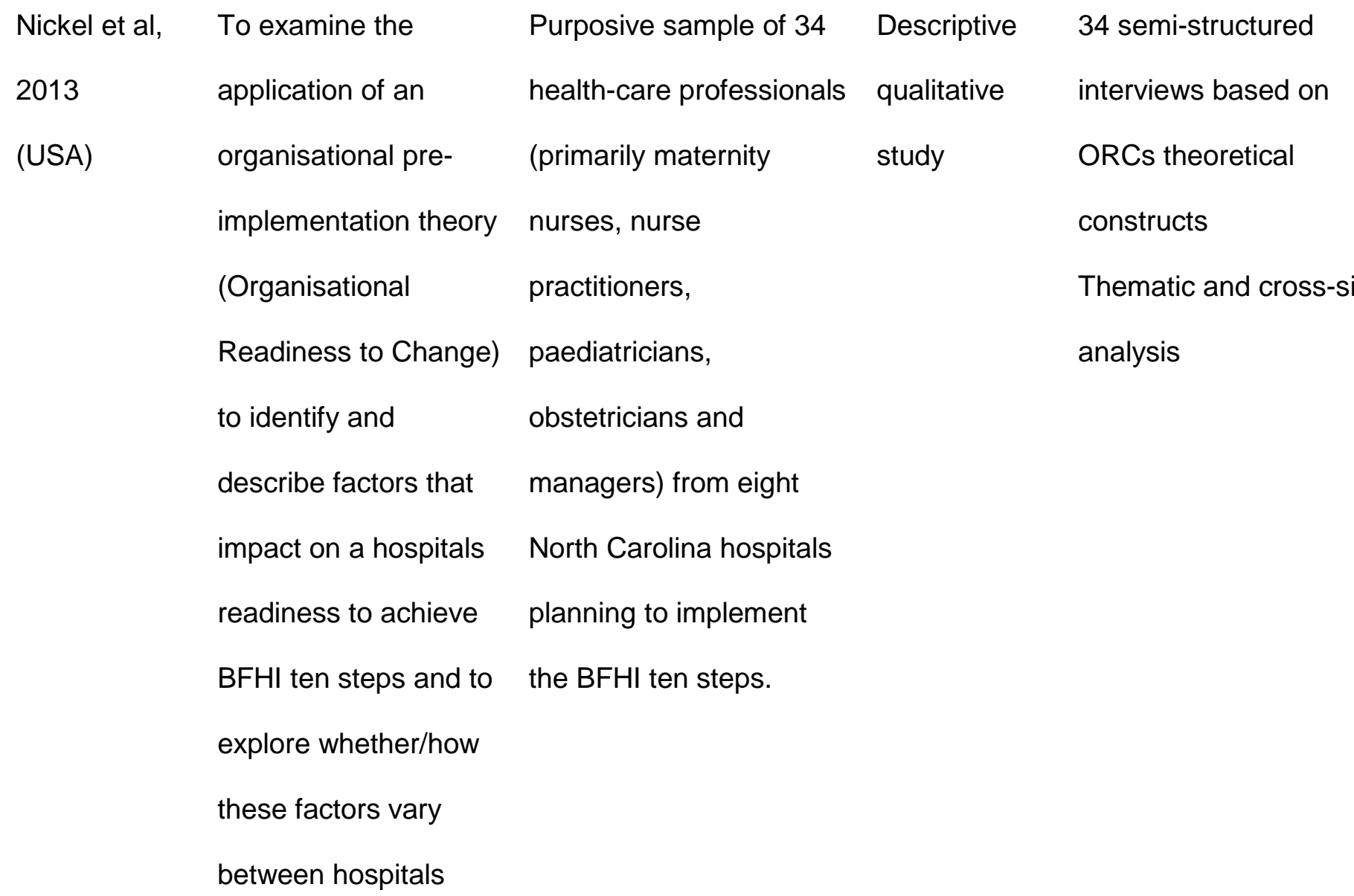

Factors influencing hospital readiness for change (arranged by the two dimensions of ORC: collective commitment \& collective efficacy)-

Related to collective commitment:

- Night versus day shift

- Management support

- Change champions

- Observing mothers utilising BF support

Related to collective efficacy:

- Staffing

- Training

- Visitors in hospital room

Related to collective commitment and 
- Perceptions of forcing versus supporting mothers

- Perceptions of mothers' culture

- Reliance on lactation consultants

\begin{tabular}{|c|c|c|c|c|c|}
\hline \multirow{2}{*}{$\begin{array}{l}\text { Reddin, } \\
\text { Pincombe \& }\end{array}$} & To explore the factors & 17 newly graduated & Qualitative & 3 semi-structured & Participant experiences are presented \\
\hline & that influence the & midwives about to & longitudinal & interviews using critical & under each of the ten steps to successful \\
\hline Darbyshire, & development of & commence a Graduate & study & incident technique & breastfeeding as the themes from the \\
\hline 2007 & breastfeeding support & Midwifery Program & & conducted with each & analysis. Overall findings suggest work \\
\hline (Australia) & practice for beginning & (GMP) were recruited & & participant over 1 year. & and time pressures act as barriers to \\
\hline & practitioner midwives & from two South & & Boyatzis' data-driven & compliance with BFHI ten steps for both \\
\hline & in relation to the $\mathrm{BFHI}$ & Australian universities & & thematic analysis. & staff and newly qualified midwives. \\
\hline & ten steps to & and one Western & & & \\
\hline & successful & Australian hospital & & & \\
\hline & breastfeeding. & & & & \\
\hline Schmied et al & To examine the & 132 health professionals & Qualitative & 10 focus groups & Three main themes were identified: \\
\hline 2011 & perceptions of $\mathrm{BFHI}$ & including midwives, & interpretive & Thematic analysis & - Belief and Commitment \\
\hline (Australia) & held by midwives and & nurses, neonatal nurses & study & & - Interpreting BFHI \\
\hline
\end{tabular}


nurses working in one

area health service in

NSW, Australia

\section{across four maternity}

units, two neonatal

intensive care units and

related community

services

\begin{tabular}{|c|c|c|c|c|c|}
\hline $\begin{array}{l}\text { Taylor et al } \\
2011\end{array}$ & $\begin{array}{l}\text { To explore the } \\
\text { attitudes and opinions }\end{array}$ & $\begin{array}{l}\text { Convenience sample of } \\
47 \text { participants; including }\end{array}$ & $\begin{array}{l}\text { An } \\
\text { exploratory }\end{array}$ & $\begin{array}{l}5 \text { focus groups }-2 \mathrm{NICU} \\
\text { groups, } 2 \text { midwife }\end{array}$ & $\begin{array}{l}\text { Four major themes emerged: } \\
\text { - It is a different world }\end{array}$ \\
\hline (Australia) & $\begin{array}{l}\text { of hospital staff } \\
\text { around the process of } \\
\text { implementation of the } \\
\text { BFHI in NICUs within } \\
\text { the context of hospital } \\
\text { environment. }\end{array}$ & $\begin{array}{l}\text { nursing and midwifery } \\
\text { staff and one } \\
\text { paediatrician. } \\
\text { Participants were } \\
\text { recruited from } 4 \\
\text { maternity units within } \\
\text { one Area Health Service } \\
\text { of NSW Australia, } 2 \text { of } \\
\text { which included a NICU. }\end{array}$ & $\begin{array}{l}\text { study using } \\
\text { naturalistic } \\
\text { methods of } \\
\text { inquiry. }\end{array}$ & $\begin{array}{l}\text { groups, one BFI } \\
\text { coordinators group and } \\
\text { one interview with a } \\
\text { paediatrician. } \\
\text { Thematic analysis }\end{array}$ & $\begin{array}{l}\text { - Separate worlds: mother and infant } \\
\text { - It is hard work } \\
\text { - It can be done }\end{array}$ \\
\hline
\end{tabular}

- Climbing a Mountain 


\begin{tabular}{|c|c|c|c|c|c|}
\hline Thomson, & to explore the & Purposive sample of 47 & a qualitative & 2 Focus groups & One global theme presented: \\
\hline Bilson \& & approach used to & participants from a & descriptive & 41 in-depth interviews. & Hearts and minds approach to BFI \\
\hline Dykes & implement the & variety of professional & study & Thematic networks & implementation. The 3 organising themes \\
\hline \multirow[t]{6}{*}{ 2012/(UK) } & community BFI award & backgrounds including & & analysis & included: \\
\hline & from the perspective & public health, local & & & - Credible leadership \\
\hline & of the professionals & councils, maternity & & & - Engagement of key partners \\
\hline & involved & services, health visiting & & & - Changing attitudes and practice \\
\hline & & services and bf voluntary & & & \\
\hline & & service. & & & \\
\hline Walsh, & First of a 3 part study & 31 health professionals & A qualitative & Focus group interviews & Seven descriptive themes presented \\
\hline Pincombe \& & to examine the factors & including midwives, & descriptive & explored opinions of 31 & outlining challenges/barriers associated \\
\hline Henderson, & perceived to promote & lactation consultants, & study & participants, in differing & with BFHI accreditation: \\
\hline 2011 & or & managers and medical & & roles and levels of & - Participants understanding differed \\
\hline \multirow[t]{3}{*}{ (Australia) } & hinder BFHI & staff from six South & & employment. & - Preconceptions and mothers' choice \\
\hline & accreditation. Primary & Australian maternity & & Thematic analysis & - The accreditation process \\
\hline & focus of this part was & hospitals. A selection & & & - Intra-organisational difficulties \\
\hline
\end{tabular}


to explore the

attitudes and

directives held by

hospital staff towards

BFHI accreditation. from BFHI accredited

and non-BFHI accredited

\section{hospitals included.}

achieving BFHI accreditation

- Implementing the ten steps

- Bottle feeding culture

- Continuation of breastfeeding and employment 
Table 2 - Themes identified in each paper

\begin{tabular}{|c|c|c|c|c|c|c|c|}
\hline & $\begin{array}{l}\text { Moore, } \\
\text { Gauld \& } \\
\text { Williams } \\
2007\end{array}$ & $\begin{array}{l}\text { Nickel et } \\
\text { al, } 2013\end{array}$ & $\begin{array}{l}\text { Reddin, } \\
\text { Pincombe } \\
\text { \& } \\
\text { Darbyshire, } \\
2007\end{array}$ & $\begin{array}{l}\text { Schmied } \\
\text { et al, } 2011\end{array}$ & $\begin{array}{l}\text { Taylor et } \\
\text { al, } 2011\end{array}$ & $\begin{array}{l}\text { Thomson, } \\
\text { Bilson } \\
\text { and } \\
\text { Dykes, } \\
2012\end{array}$ & $\begin{array}{l}\text { Walsh, } \\
\text { Pincombe } \\
\text { \& } \\
\text { Henderson, } \\
2011\end{array}$ \\
\hline \multicolumn{8}{|l|}{$\begin{array}{l}\text { Desirable innovation or an unfriendly } \\
\text { imposition? }\end{array}$} \\
\hline - Healthy lives, healthy communities & $\checkmark$ & $\checkmark$ & & $\checkmark$ & $\checkmark$ & $\checkmark$ & $\checkmark$ \\
\hline - Mother 'unfriendly' & & $\checkmark$ & $\checkmark$ & $\checkmark$ & & & $\checkmark$ \\
\hline - Competing priorities & $\checkmark$ & $\checkmark$ & $\checkmark$ & $\checkmark$ & & & $\checkmark$ \\
\hline - Overwhelmed by requirements & $\checkmark$ & & $\checkmark$ & $\checkmark$ & $\checkmark$ & $\checkmark$ & $\checkmark$ \\
\hline \multicolumn{8}{|l|}{$\begin{array}{l}\text { Cultural and Organisational Constraints } \\
\text { and Obstacles }\end{array}$} \\
\hline - Rationalising, excusing, blaming & $\checkmark$ & $\checkmark$ & $\checkmark$ & $\checkmark$ & $\checkmark$ & $\checkmark$ & $\checkmark$ \\
\hline \multicolumn{8}{|l|}{$\begin{array}{l}\text { Seizing the positive and being } \\
\text { collaborative }\end{array}$} \\
\hline $\begin{array}{l}\text { - Building on the positive, one step at } \\
\text { a time }\end{array}$ & $\checkmark$ & & $\checkmark$ & $\checkmark$ & $\checkmark$ & & \\
\hline - A dedicated and credible leader & $\checkmark$ & & & $\checkmark$ & & $\checkmark$ & \\
\hline $\begin{array}{l}\text { - Top-down approach: 'A directive is } \\
\text { needed' }\end{array}$ & $\checkmark$ & $\checkmark$ & & $\checkmark$ & & & \\
\hline $\begin{array}{l}\text { A 'softly-softly' collaborative } \\
\text { approach }\end{array}$ & $\checkmark$ & & & & & $\checkmark$ & $\checkmark$ \\
\hline
\end{tabular}

